\title{
Detailed computed tomography insight into the mechanism of complex bioprosthetic tricuspid valve dysfunction in a patient with Ebstein's anomaly.
}

Rajmund Bobrowski ${ }^{1, A-B, D}$, Łukasz Kalińczuk ${ }^{1, A-F}$, Michał Świerczewski ${ }^{1, A, C-D}, K^{1}$ Kornelia Rynkiewicz ${ }^{1, E}$, Wiktor Skotarczka ${ }^{1, \mathrm{~A}, \mathrm{D}-\mathrm{E}}$, Kamil Zieliński $^{1, \mathrm{D}-\mathrm{E}}$, Ilona Michałowska ${ }^{1, \mathrm{E}}$, Marcin Demkow ${ }^{1, \mathrm{E}}$

A - Research concept and design, B - Collection and/or assembly of data, C - Data analysis and interpretation,

D - Writing the article, E - Critical revision of the article, F - Final approval of article

1 Institute of Cardiology, Department of Coronary and Structural Heart Diseases

Address for correspondence:

Rajmund Bobrowski, Institute of Cardiology, Department of Coronary and Structural Heart Diseases email: rajmund.bobrowski@gmail.com

Łukasz Kalińczuk, Institute of Cardiology, Department of Coronary and Structural Heart Diseases email: lukasz.kalinczuk@gmail.com

Michał Świerczewski, Institute of Cardiology, Department of Coronary and Structural Heart Diseases email: swierczewski.michal@yahoo.pl

Kornelia Rynkiewicz, Institute of Cardiology, Department of Coronary and Structural Heart Diseases email: rynkiewiczkornelia@gmail.com

Wiktor Skotarczka, Institute of Cardiology, Department of Coronary and Structural Heart Diseases email: wiktorskoti@wp.pl

Kamil Zieliński, Institute of Cardiology, Department of Coronary and Structural Heart Diseases email: kamilziel@gmail.com

Ilona Michałowska, Institute of Cardiology, Department of Coronary and Structural Heart Diseases email: imichalowska@ikard.pl

Marcin Demkow, Institute of Cardiology, Department of Coronary and Structural Heart Diseases email: mdemkow@ikard.pl

Received: 2019-12-30

Revised:

Accepted: 2019-12-30

Final review:

DOI: $10.24255 / \mathrm{hbj} / 115999$

\section{Key words:}

computed tomography, bioprosthesis, transcatheter valve implantation

A 37-year-old man with Ebstein's anomaly was admitted due to right ventricle dysfunction presenting with peripheral edema and worsening dyspnea on exertion (NYHA 3). The patient had five prior sternotomies with implantation of the following valves at the site of the tricuspid position: ${ }^{(1)}$ a 31mm CarboMedicis mechanical valve (Austin, TX) in 1996, ${ }^{(2)}$ a 31-mm St. Jude Medical mechanical valve (St. Paul, MN) in 1997, (3) a 33-mm St. Jude Medical bioprosthesis in 2000, and the latest insertion of (4) a 29-mm Carpentier-Edwards Magna bioprosthesis (Edwards Lifesciences, Irvine, Calif) in 2010 for recurrent bioprosthesis stenosis. Two-dimensional transthoracic echocardiography showed normal left ventricular function and a significantly dilated right ventricle (right outflow tract diameter of $34 \mathrm{~mm}$, inflow tract of $52 \mathrm{~mm}$ and diastole area of $36.5 \mathrm{~cm}^{2}$ ). It revealed severe bioprosthesis regurgitation and its concomitant stenosis (mean pressure gradient $>5 \mathrm{mmHg}$ ). The dual-source 384-row computed tomography (CT, SOMATOM Force, Siemens Healthineers, Erlangen, Germany) confirmed typical features of Ebstein's anomaly signified by apical displacement of the septal and posterior leaflet of the tricuspid valve into the substantially enlarged right ventricular cavity (Figure $1 \mathrm{~A}$ ). Notably, CT allowed for detailed insight into the anatomy of the bioprosthesis and the possible mechanism of its dysfunction. The inner valve stent diameter was $2.90 \mathrm{~cm}$, with a cross-sectional area of $6.17 \mathrm{~cm}^{2}$. Severe calcifications were seen at the level of the valve sewing ring and along each of the cusp commissures but only mild calcification of cusps' free margins were noted (Figure 1, B-C). The lumen cross-sectional area (LCSA) measured correspondingly at the level of the bioprosthesis ring and the cusp free margins were 
$4.90 \mathrm{~cm}^{2}$ and $2.40 \mathrm{~cm}^{2}$ in diastole versus $4.40 \mathrm{~cm}^{2}$ and $1.40 \mathrm{~cm}^{2}$ in systole (Fig. 1, B-C vs E-F; respectively). Leaflet restriction was calculated by measuring the distance from the midpoint of the free margin of each leaflet to the stent border and divided by the radius of the valve lumen area during diastole. The calculated values were as follows: $55.17 \%, 50.55 \%, 38.06 \%$ (whereas $>90 \%$ is ideal). The coaptation defect (LCSA systole/ LCSA diastole- $x 100 \%$ ) was $58.33 \%$, which stands for the percentage of the valve's stenotic orifice which undergoes a coaptation defect. The patient underwent catheterization, with a tricuspid diastolic pressure gradient of $5 \mathrm{mmHg}$, and a mean right atrial pressure of $11 \mathrm{mmHg}$. Due to the high surgical risk (EuroSCORE II of 4.64\%) with five prior sternotomies, the patient was qualified for balloon-expandable transcatheter heart valve implantation with a 29-mm Edwards SAPIEN 3 bioprosthesis (Edwards Lifesciences Irvine, Calif) with overfilling of the deployment balloon $(+3 \mathrm{ml})$. The procedure was successful with a final tricuspid diastolic pressure gradient of $2 \mathrm{mmHg}$ with no valve insufficiency as assessed in angiography and echocardiography. Eventually, the patient made an uneventful postprocedural recovery.
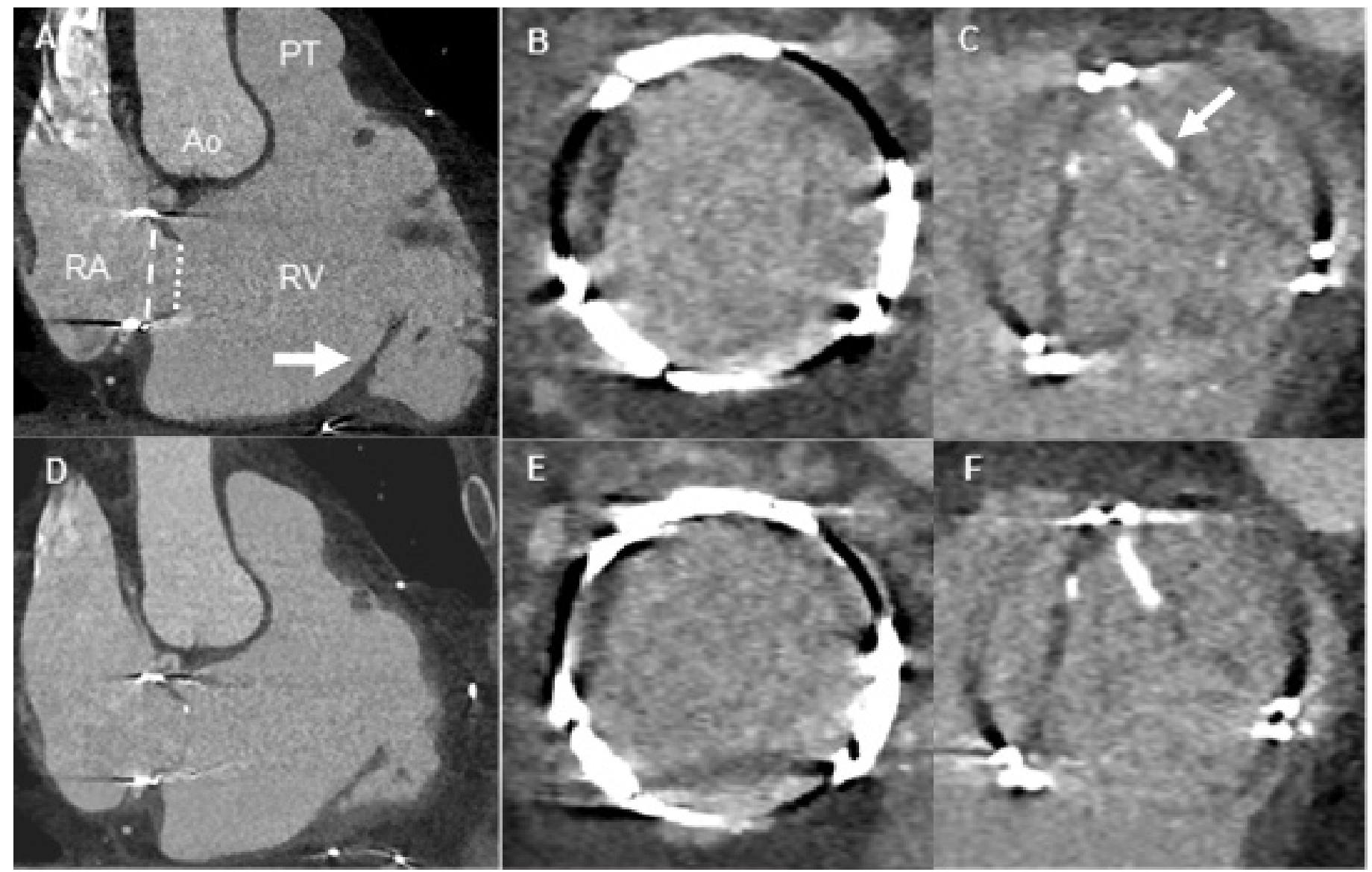

Figure 1. Computed tomography results: The end-diastole long-axis view demonstrates apical displacement of the posterior leaflet of the tricuspid valve (white arrow) into the right ventricular cavity and 31-mm Carpentier-Edwards Magna bioprosthesis in the proper tricuspid position (A). The corresponding end-diastole short axis images obtained at the level of the bioprosthesis sewing ring (B, white dashed line in the long-axis view) and cusps' free margins (C, white dotted line in the long-axis view), with visualized defect areas and localized calcium deposits (white arrow). The corresponding end-systole long-axis view of the bioprosthesis (D) with its short axis views (E-F) RA - right atrium, RV - right ventricle, Ao - aorta, PT - pulmonary trunk 